\title{
Erythropoietin in vasospasm. From bench to bedside?
}

\author{
Leonardo Christiaan Welling ${ }^{1}$, Mariana Schumacher Welling ${ }^{2}$, \\ Eberval Gadelha Figueiredo 3 , Manoel Jacobsen Teixeira ${ }^{4}$
}

State University of Ponta Grossa (UEPG), Ponta Grossa, PR, Brazil; University of Sao Paulo (USP), Sao Paulo, SP, Brazil

\begin{abstract}
Aneurysmal subarachnoid haemorrhage is one of the most deleterious acute neurological diseases. The cerebral ischemia secondary to arterial vasospasm occurring after aneurysmal subarachnoid haemorrhage is still responsible for the considerable morbidity and mortality in these patients. Besides the knowledge of basic mechanisms of cerebral vasoespasm following aneurysmal subarachnoid haemorrhage, the prophylaxis and treatment of this pathology however still remain suboptimal. There is some evidence that acute erythropoietin treatment may reduce the severity of cerebral vasospasm and eventually improve outcome in aneurysmal subarachnoid haemorrhage patients. There are underlying mechanisms extend far beyond erythropoiesis: like enhancing neurogenesis, decreasing inflammation and apoptosis inhibition. In this review the authors describe many of the biologic effects, especially experimental studies and clinical studies that reported why the erythropoietin could be beneficial to patients with aneurysmal subarachnoid haemorrhage.
\end{abstract}

\section{KEYWORDS}

Subarachnoid hemorrhage, vasospasm intracranial, erythropoietin.

\section{RESUMO}

Eritropoietina no vasoespasmo. Da bancada do laboratório para a beira do leito?

A hemorragia subaracnóidea é uma das doenças neurológicas agudas mais graves. A isquemia cerebral secundária ao vasoespasmo arterial após a hemorragia ainda é responsável por considerável morbidade e mortalidade nesses pacientes. Ao lado do conhecimento dos mecanismos básicos do vasoespasmo na hemorragia subaracnóidea, a profilaxia e o tratamento dessa entidade ainda são insuficientes. Há evidências de que o uso da eritropoietina na fase aguda pode reduzir a gravidade do vasoespasmo e, eventualmente, melhorar o prognóstico desses pacientes. Há mecanismos de ação da eritropoietina que vão além da eritropoiese como neurogênese, redução da inflamação e inibição da apoptose. Nesta revisão, os autores elucidam inúmeros efeitos biológicos, principalmente aqueles demonstrados nos estudos experimentais e clínicos que descrevem por que a eritropoietina pode ser benéfica em pacientes com hemorragia subaracnóidea.

\section{PALAVRAS-CHAVE}

Hemorragia subaracnóidea, vasoespasmo intracraniano, eritropoietina.

1 Neurosurgeon, assistant professor of State University of Ponta Grossa (UEPG), Ponta Grossa, PR, Brazil.

2 Medicine student of UEPG, Ponta Grossa, PR, Brazil.

3 Neurosurgeon, assistant professor of University of Sao Paulo (USP), Sao Paulo, SP, Brazil.

4 Neurosurgeon, full professor of USP, Sao Paulo, SP, Brazil. 


\section{Introduction}

Aneurysmal subarachnoid haemorrhage (SAH) is one of the most deleterious acute neurological diseases. Mortality is approximately $50 \%$ (including pre-hospital deaths) and around $30 \%$ of the survivors remain dependent. ${ }^{1}$ Cerebral vasospasm and the resulting cerebral ischemia occurring after subarachnoid hemorrhage (SAH) are still responsible for the considerable morbidity and mortality in patients affected by cerebral aneurysms. Delayed ischemic deficits due to vasospasm complicate the course of $15 \%$ to $36 \%$ of patients after aneurysmal subarachnoid hemorrhage and account for $13.5 \%$ of in-patient mortality and morbidity.

Strategies to prevent and treat cerebral vasospasm include hyperdynamic therapy and calcium channel blockers. ${ }^{2}$ Other prophylactic agents such as endothelin A receptor antagonists were effective in experimental and animal settings but failed to improve outcome in human trials. ${ }^{3}$ More aggressive management with transluminal balloon angioplasty is a commonly used approach that has been shown to effectively reverse large-artery vasospasm. ${ }^{4}$ However, it may not be effective when used as prophylactic treatment to prevent vasospasm and subsequent ischemia. Besides the knowledge of basic mechanisms of cerebral vasoespasm following $\mathrm{SAH}$, the prophylaxis and treatment of this pathology however still remain suboptimal.

Although several clinical trials have studied potential neuroprotective agents in patients with SAH no broadly applicable, safe and efficacious treatment has been identified. ${ }^{1}$ There is some evidence that acute erythropoietin (EPO) treatment may reduce the severity of cerebral vasospasm and eventually improve outcome in SAH patients. There are underlying mechanisms extend far beyond erythropoiesis: like enhance neurogenesis, decrease inflammation and inhibit apoptosis especially in the damaged brain where EPO receptors are highly expressed. ${ }^{5,6}$ Timing of EPO treatment in the early phase of SAH may be crucial, ${ }^{78}$ however, the acute effect of $\mathrm{EPO}$ on brain homeostasis in severe cerebral vasospasm has not been elucidated so far. In this review the authors describe a many of the biologic effects of EPO that could be beneficial to patients with SAH.

\section{Physiopathology of cerebral vasospasm}

After aneurysmal rupture, in the first hours following bleeding, the exposure of cerebral arteries on the surface of the brain to the resulting blood clot causes alterations in vascular reactivity. ${ }^{8} \mathrm{Abnormalities}$ of ce- rebral artery function, such as impaired vasodilatation and increased vasoconstriction, are thought to cause major complications in SAH patients.

Using angiographic visualization, Ecker and Riemenschneider were the first to report cerebral vasospasm (Figure 1). In their work the presence of vasoespasm was correlated with a 1.5- to 3 -fold increase in mortality in the first two weeks after SAH. ${ }^{9}$ It begins to appear 3-4 days, reaches its maximum incidence and severity between 7-10 days and usually resolves 12-14 days after a single $\mathrm{SAH} .{ }^{10}$

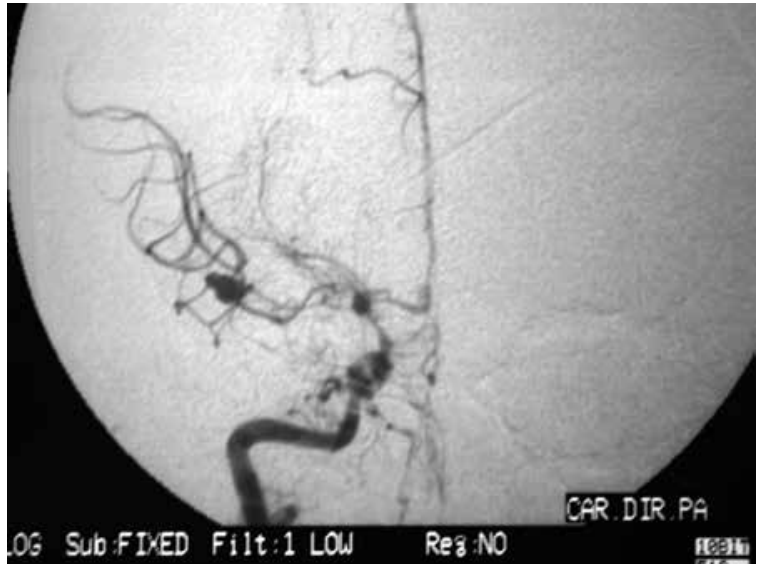

Figure 1 - Angiographic diameter reduction in cerebral vasospasm.

Vasospasm is chiefly a hemodynamic problem. Superimposed thromboembolic mechanisms have been postulated to contribute, but their importance remains speculative. ${ }^{11,12}$ Whether or not a patient with angiographic vasospasm develops symptomatic vasospasm depends on the length and severity of the arterial narrowing. Other factors that influence cerebral blood flow (CBF) are involved as blood pressure, intracranial pressure, blood volume, cardiac output, viscosity, anastomotic blood supply and brain metabolic demand that is influenced by temperature, seizures and drugs. Symptoms and signs probably do not develop unless there is $>50 \%$ angiographic diameter reduction. The peak day of onset of symptomatic vasospasm is eight days after $\mathrm{SAH}$ or one day after the peak of angiographic vasospasm..$^{11,12}$ The most powerful predictor of vasospasm is the volume, density and prolonged presence of subarachnoid blood, usually as observed on computed tomography (CT) scan, around the arteries that develop vasospasm ${ }^{13,14}$ (Figure 2).

The pathogenesis of delayed cerebral vasospasm is related to a number of physical and chemical processes, including endothelial damage and smooth muscle cell contraction resulting from spasmogenic substances generated during lysis of subarachnoid blood clots, ${ }^{15}$ changes in vascular responsiveness and inflammatory or immunological reactions of the vascular wall. ${ }^{5,15}$ 


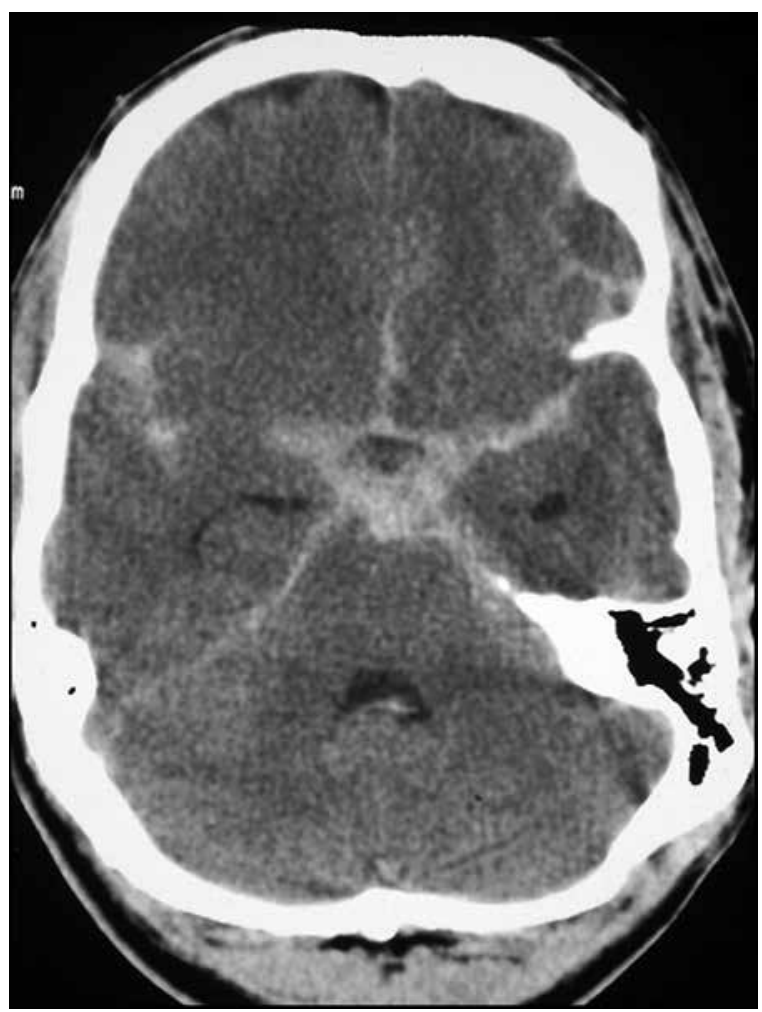

Figure 2 - Presence of subarachnoid blood as observed on computed tomography scan.

Cerebral arterial blood vessel tone is balanced by vasoconstrictor and dilator systems designed to achieve equilibrium, depending on several factors. It is widely accepted that it is able to modulate vascular smooth muscle function through the release of endothelialderived relaxing factors (EDRF), the most important substance being nitric oxide $(\mathrm{NO})^{5}$ but also prostaglandin derivatives ${ }^{16}$ and hyperpolarization factors. ${ }^{17}$ On the other hand, endothelial cells also produce vasoconstrictor substances, the so-called endothelialderived contracting factors (EDCF), the most potent being the peptide endothelin..$^{18}$ Inhibiting the release of EDRF and/or increasing the production of EDCF as well as increasing the contractility of the actin-myosin filaments by increasing the smooth muscle calcium pool or calcium sensitivity of the contractile filaments will cause an increase in vascular tone. Therefore, each single metabolic pathway in either the endothelial or smooth muscle cells that causes dilation or reduces constriction is a potential target for $\mathrm{SAH}$-induced vasospasm.

\section{Erythropoietin - Background}

Erythropoietin (EPO), a $34-\mathrm{kDa}$ glycoprotein, is the primary hormone that regulates the differentiation and proliferation of immature erythroid cells ${ }^{19} \mathrm{EPO}$ production in these organs is upregulated during tissue hypoxia through an oxygen-sensing pathway mediated by hypoxia-inducible factor. ${ }^{20}$ Following the purification of EPO in 1977 in urines from patients with aplastic anemia, ${ }^{21}$ the first recombinant human EPO (rhEPO) became available in treating anemia with chronic kidney disease (CKD) and chemotherapy-induced anemia associated with non-myeloid malignancies.

In addition to stimulating erythropoiesis, other effects of EPO have been discovered that may be of benefit to patients with a variety of central nervous system injuries. ${ }^{22}$ Normal brain expresses low levels of EPO and EPO receptor but these increases after traumatic brain injury, subarachnoid hemorrhage, and ischemic stroke. EPO and an EPO receptor appear in neurons, glia, neuroprogenitor cells, and cerebrovascular endothelial cells. In vitro studies have revealed that EPO promotes survival in cultured neurons after hypoxia, serum deprivation, and glutamate/AMPA/kainic acid excitotoxicity. Further exploration has demonstrated that EPO also has neuroprotective effects in vivo after hypoxic-ischemic, traumatic, excitotoxic, and inflammatory injuries in rodents. ${ }^{23,24}$ The knowledge of neuroprotective effects of EPO stimulates the development of bench studies involving this glycoprotein.

\section{Erythropoietin - Experimental studies in vasospasm}

Many of the biologic effects of EPO could be beneficial to patients with SAH, even the side effect of hypertension. Stimulation of erythropoiesis might be beneficial in patients with SAH. Transfusion may be detrimental and there is some evidence to suggest maintaining a low-normal hematocrit is beneficial.

Buemi et al. ${ }^{25}$ were the first to report in vivo effects of EPO in an animal model of SAH. By injecting autologous blood into the cisterna magna in rabbits, they found that intraperitoneal administration of rhEPO improved both locomotor activity and animal survival. Expanding on the work in this model, it has been demonstrated that systemic rhEPO also significantly decreases basilar artery vasoconstriction, improves clinical neurologic status, decreases neuronal necrosis, and attenuates levels of glial-generated S-100 protein (a CSF marker of brain damage). According to Murphy et al. ${ }^{26}$ recombinant human EPO improves autoregulation of $\mathrm{CBF}$ after $\mathrm{SAH}$, and therefore it may be a promising treatment for cerebral ischemia resulting from delayed vasospasm. In this investigation, the authors reported that treatment with rhEPO after experimental SAH is 
associated with reduced mortality rates, improved CBF, and fewer neurological sequelae.

Santhanam et al. ${ }^{27}$ examined the impact of local adenovirus-mediated delivery of rhEPO by injecting adenovirus containing the rhEPO gene (AdEPO) into the cisterna magna of rabbits after SAH. They demonstrated that SAH-induced basilar artery vasospasm was significantly attenuated in animals treated with AdEPO. In this study, EPO led to increased expression of the phosphorylated form of endothelial nitric oxide synthase (eNOS) and augmented cyclic GMP levels. The authors postulate that in this model for SAH, EPO may protect against vasospasm through NO-mediated smooth muscle relaxation.

Many studies tested the protective effects of EPO using intraventricular injections to bypass the BBB. However, because intrathecal delivery of EPO is often impractical in humans, the ability of EPO to cross the BBB is critical for its utility as a clinical application. In studies where EPO was administered intravenously at doses appropriate for stimulating erythropoiesis (200-400 U/kg), EPO was not detectable in the central nervous system (CNS). ${ }^{28,29}$ However, at much higher doses (2,000-30,000 U/kg), EPO can cross the BBB in quantities sufficient to provide neuroprotection. The high dosing that is required for neuroprotection has led to concerns about potential adverse consequences of treatment with EPO. Although some investigators have demonstrated that high-dose EPO is safe in rats and humans others have reported EPO-induced complications such as hypertension, thrombosis, and decreased renal blood flow. ${ }^{30}$ It is suggested that the CNS may express a version of the receptor that is distinct from the form expressed within the hematopoietic system. Because of these observed differences in receptor properties and the concern of adverse effects associated with highdose EPO, scientists have attempted to design EPO derivatives to maximize tissue-protective potential while limiting unwanted erythropoietic effects. Of the tested compounds, carbamylated EPO (CEPO) appears to have the greatest selectivity for EPO in the CNS and has been demonstrated to provide neuroprotection after brain injury without stimulating erythropoiesis. ${ }^{31}$

With substantial evidence for EPO neuroprotective effects, other studies examining the underlying mechanisms have proliferated. Some of the proposed mechanisms for neuroprotection now include inhibition of apoptosis enhanced neurogenesis, ${ }^{31}$ reduced excitotoxicity, ${ }^{32}$ modulation of $\mathrm{NO},{ }^{33}$ antioxidant effects, ${ }^{34}$ modulation of neurotransmitter release, ${ }^{24}$ vascular protection by preserving endothelial cell integrity and by promoting angiogenesis. ${ }^{35}$ Taken collectively, these studies demonstrate that administration of EPO markedly has neuroprotective effects, attenuates vasospasm,
CBF impairment and the consequent cerebral ischemia after experimental SAH.

\section{Erythropoietin - Clinical studies in vasospasm}

With these reported neuroprotective effects in animals, investigators began to examine the effects of EPO in treating neurologic dysfunction in humans. In 2002, Ehrenreich et al. ${ }^{36}$ published a pivotal clinical trial in ischemic stroke patients, demonstrating that highdose recombinant human EPO (rhEPO) administered within 8 hours of symptom onset, protected against brain injury, reduced infarct size, and improved clinical outcome. These data generated strong interest in the neuroprotective potential of high-dose EPO in humans. Given what is known about the pathophysiology of SAH and the mechanisms of EPO-mediated neuroprotection, EPO became an attractive option for treating patients with SAH.

Springborg et al. ${ }^{7}$ conducted the first double-blinded trial to examine the impact of rhEPO in patients after SAH. In this trial, 73 patients with CT-verified spontaneous $\mathrm{SAH}$ were randomized to treatment with either intravenous rhEPO $(500 \mathrm{U} / \mathrm{kg} /$ day $)$ or placebo for three days. Multiple parameters were recorded, including the severity of SAH neurologic status, daily transcranial Doppler measurements, cerebrospinal fluid levels of S-100 protein, neuron-specific enolase. The primary endpoint was the dichotomous Glasgow Outcome Score but the number of patients was too small to show any effect on this. In terms of safety, no comment was made about venous thromboembolic or other events, although no side effects of EPO were reported. Interestingly, blood pressure was significantly higher in the EPO-treated patients. ${ }^{7}$

Recently, Tseng et al. ${ }^{6}$ reported results from a second randomized, double blind, placebo-controlled trial. Eighty patients with aneurysmal SAH were randomized to receive placebo or 90,000 U EPO over the course of 48 hours. Transcranial Doppler ultrasonography was employed to assess vasospasm incidence, duration, and severity. Delayed ischemic neurological deficits (DIND) and outcomes at discharge and at six months were also recorded. Results indicated that although EPO treatment did not impact the overall incidence of vasospasm, it significantly reduced the incidence of severe vasospasm, the incidence of DIND with new cerebral infarcts, and the duration of impaired autoregulation. Patients in the EPO group also had higher clinical scores at discharge, but these effects were not observed at the 6-month follow-up, which authors at least partially attribute to 
inadequate statistical power. Adverse events were not significantly different between groups. This study provides new evidence for the potential benefit and relative safety of EPO for the treatment of SAH in humans. ${ }^{6}$

Helbok et al. ${ }^{37}$ reported that high-dose systemic EPO treatment increases brain tissue oxygen tension in patients with severe vasospasm after SAH. The present data are of potential importance because they support the hypothesis of a beneficial effect of high-dose systemic EPO beyond erythropoeisis on human brain tissue.

However, given the high systemic doses that are required for neuroprotection, EPO's safety in humans has been a major concern. At high doses, rhEPO has the potential for a variety of hematopoietic complications. With the hypercoagulopathy that has been associated with SAH, EPO's increased risk of thrombosis ${ }^{31}$ is of particular concern in this specific patient population. These hemodynamic effects could also be problematic in patients with comorbid conditions, such as hypertension, congestive heart failure, and coagulopathy. To address the concern of rhEPO's adverse effects at high doses derivatives of EPO have recently been introduced. With selectivity for the brain, the EPO derivative, CEPO, has no erythropoietic effects and may be a safer alternative for neuroprotection in humans. Results from a phase I clinical trial examining the safety of CEPO for treating patients with acute ischemic stroke are pending and highly anticipated.

\section{Conclusion}

Vasospasm-related cerebral ischemia is common and significantly impacts on outcome after aneurysmal subarachnoid hemorrhage.

Although mechanisms underlying cerebrovascular dysfunction after aneurysmal SAH are much better understood now than a few year ago, they still need further investigations. It is now widely accepted that endothelial damage and smooth muscle cell contraction resulting from spasmogenic substances, changes in vascular responsiveness and inflammatory or immunological reactions of the vascular wall contribute to the development of cerebrovascular dysfunction following aneurysmal SAH.

Finally, in terms of pharmacological management, a number of experimental studies demonstrate the preventive and/or therapeutic potentials of new drugs in vivo and in vitro. Among these, systemically administered rHuEPO has recently been found to produce a clear neuroprotective action during SAH. These beneficial effects strongly support that it may represent a valid neuroprotective therapeutic solution in humans.
However, although it has proven safe and effective in the setting of a wide range of diseases and drug treatments, the erythropoietic effects may limit the clinical use of erytrophoietin. For future trials, design issues include dose, duration, and type of EPO to administer; outcome measures to employ that would be sensitive to EPO effects; and patient populations to study. Nevertheless, the work so far suggests EPO for SAH should be pursued.

\section{References}

1. van Gijn J, Rinkel GJ. Subarachnoid haemorrhage: diagnosis, causes and management. Brain. 2001;124(Pt 2):249-78.

2. Ferro JM, Canhão P, Peralta R. Update on subarachnoid haemorrhage. J Neurol. 2008;255(4):465-79.

3. Macdonald RL, Higashida RT, Keller E, Mayer SA, Molyneux A, Raabe A, et al. Clazosentan, an endothelin receptor antagonist, in patients with aneurysmal subarachnoid haemorrhage undergoing surgical clipping: a randomised, double-blind, placebo-controlled phase 3 trial (CONSCIOUS-2). Lancet Neurol. 2011;10(7):618-25.

4. Eddleman CS, Hurley MC, Naidech AM, Batjer HH, Bendok BR. Endovascular options in the treatment of delayed ischemic neurological deficits due to cerebral vasospasm. Neurosurg Focus. 2009;26(3):E6.

5. Pluta RM. Delayed cerebral vasospasm and nitric oxide: review, new hypothesis, and proposed treatment. Pharmacol Ther. 2005;105(1):23-56.

6. Tseng MY, Hutchinson PJ, Richards HK, Czosnyka M, Pickard JD, Erber WN, et al. Acute systemic erythropoietin therapy to reduce delayed ischemic deficits following aneurysmal subarachnoid hemorrhage: a Phase II randomized, double-blind, placebo-controlled trial. Clinical article. J Neurosurg. 2009;111(1):171-80.

7. Springborg JB, Møller C, Gideon P, Jørgensen OS, Juhler $\mathrm{M}$, Olsen NV. Erythropoietin in patients with aneurysmal subarachnoid haemorrhage: a double blind randomised clinical trial. Acta Neurochir (Wien). 2007;149(11):1089-101.

8. Pluta RM, Hansen-Schwartz J, Dreier J, Vajkoczy P, Macdonald RL, Nishizawa S, et al. Cerebral vasospasm following subarachnoid hemorrhage: time for a new world of thought. Neurol Res. 2009;31(2):151-8.

9. Ecker A, Riemenschneider PA. Arteriographic demonstration of spasm of the intracranial arteries, with special reference to saccular arterial aneurysms. J Neurosurg. 1951;8(6):660-7.

10. Weir B, Grace M, Hansen J, Rothberg C. Time course of vasospasm in man. J Neurosurg. 1978;48(2):173-8.

11. Kassell NF, Torner JC, Haley EC Jr, Jane JA, Adams HP, Kongable GL. The International Cooperative Study on the Timing of Aneurysm Surgery. Part 1: Overall management results. J Neurosurg. 1990;73(1):18-36.

12. Suzuki S, Suzuki M, Iwabuchi T, Kamata Y. Role of multiple cerebral microthrombosis in symptomatic cerebral vasospasm: with a case report. Neurosurgery. 1983;13(2):199-203.

13. Fisher CM, Kistler JP, Davis JM. Relation of cerebral vasospasm to subarachnoid hemorrhage visualized by computerized tomographic scanning. Neurosurgery. 1980;6(1):1-9. 
14. Reilly C, Amidei C, Tolentino J, Jahromi BS, Macdonald RL. Clot volume and clearance rate as independent predictors of vasospasm after aneurysmal subarachnoid hemorrhage. J Neurosurg. 2004;101(2):255-61.

15. Peterson JW, Kwun BD, Hackett JD, Zervas NT. The role of inflammation in experimental cerebral vasospasm. J Neurosurg. 1990;72(5):767-74.

16. Dumont AS, Dumont RJ, Chow MM, Lin CL, Calisaneller $\mathrm{T}$, Ley KF, et al. Cerebral vasospasm after subarachnoid hemorrhage: putative role of inflammation. Neurosurgery. 2003;53(1):123-33.

17. Chen G, Suzuki H, Weston AH. Acetylcholine releases endothelium-derived hyperpolarizing factor and EDRF from rat blood vessels. Br J Pharmacol. 1988;95(4):1165-74.

18. Zimmermann M, Seifert V. Endothelin and subarachnoid hemorrhage: an overview. Neurosurgery. 1998;43(4):863-75.

19. Jelkmann W. Biology of erythropoietin. Clin Investig. 1994;72(Suppl 6):3-10.

20. Sasaki R. Pleiotropic functions of erythropoietin. Intern Med. 2003;42(2):142-9.

21. Miyake T, Kung CK, Goldwasser E. Purification of human erythropoietin. J Biol Chem. 1977;252(15):5558-64.

22. Xiong $\mathrm{Y}$, Mahmood A, Chopp M. Emerging treatments for traumatic brain injury. Expert Opin Emerg Drugs. 2009;14(1):67-84.

23. Kawakami M, Sekiguchi M, Sato K, Kozaki S, Takahashi M. Erythropoietin receptor-mediated inhibition of exocytotic glutamate release confers neuroprotection during chemical ischemia. J Biol Chem. 2001;276(42):39469-75.

24. Mahmood A, Lu D, Qu C, Goussev A, Zhang ZG, Lu $C$, et al. Treatment of traumatic brain injury in rats with erythropoietin and carbamylated erythropoietin. J Neurosurg. 2007;107(2):392-7.

25. Buemi M, Grasso G, Corica F, Calapai G, Salpietro FM, Casuscelli $\mathrm{T}$, et al. In vivo evidence that erythropoietin has a neuroprotective effect during subarachnoid hemorrhage. Eur J Pharmacol. 2000;392(1-2):31-4.

26. Murphy AM, Xenocostas A, Pakkiri P, Lee TY. Hemodynamic effects of recombinant human erythropoietin on the central nervous system after subarachnoid hemorrhage: reduction of microcirculatory impairment and functional deficits in a rabbit model. J Neurosurg. 2008;109(6):1155-64.

27. Santhanam AV, Smith LA, Akiyama M, Rosales AG, Bailey KR, Katusic ZS. Role of endothelial NO synthase phosphorylation in cerebrovascular protective effect of recombinant erythropoietin during subarachnoid hemorrhage-induced cerebral vasospasm. Stroke. 2005;36(12):2731-7.
28. Juul SE, Harcum J, Li Y, Christensen RD. Erythropoietin is present in the cerebrospinal fluid of neonates. J Pediatr. 1997;130(3):428-30.

29. Juul SE, McPherson RJ, Farrell FX, Jolliffe L, Ness DJ, Gleason CA. Erytropoietin concentrations in cerebrospinal fluid of nonhuman primates and fetal sheep following high-dose recombinant erythropoietin. Biol Neonate. 2004;85(2):138-44.

30. Coleman TR, Westenfelder C, Tögel FE, Yang Y, Hu Z, Swenson L, et al. Cytoprotective doses of erythropoietin or carbamylated erythropoietin have markedly different procoagulant and vasoactive activities. Proc Natl Acad Sci U S A. 2006;103(15):5965-70.

31. Wang L, Zhang Z, Wang Y, Zhang R, Chopp M. Treatment of stroke with erythropoietin enhances neurogenesis and angiogenesis and improves neurological function in rats. Stroke. 2004;35(7):1732-7.

32. Yoo JY, Won YJ, Lee JH, Kim JU, Sung IY, Hwang SJ, et al. Neuroprotective effects of erythropoietin posttreatment against kainate-induced excitotoxicity in mixed spinal cultures. J Neurosci Res. 2009;87(1):150-63.

33. Noguchi CT, Asavaritikrai P, Teng R, Jia Y. Role of erythropoietin in the brain. Crit Rev Oncol Hematol. 2007;64(2):159-71.

34. Diaz Z, Assaraf MI, Miller WH Jr, Schipper HM. Astroglial cytoprotection by erythropoietin pre-conditioning: implications for ischemic and degenerative CNS disorders. J Neurochem. 2005;93(2):392-402.

35. Chong ZZ, Kang JQ, Maiese K. Apaf-1, Bcl-xL, cytochrome $c$, and caspase- 9 form the critical elements for cerebral vascular protection by erythropoietin. J Cereb Blood Flow Metab. 2003;23(3):320-30.

36. Ehrenreich H, Hasselblatt M, Dembowski C, Cepek L, Lewczuk P, Stiefel M, et al. Erythropoietin therapy for acute stroke is both safe and beneficial. Mol Med. 2002;8(8):495505.

37. Helbok R, Shaker E, Beer R, Chemelli A, Sojer M, Sohm F, et al. High dose erythropoietin increases brain tissue oxygen tension in severe vasospasm after subarachnoid hemorrhage. BMC Neurol. 2012;12:32.

\section{Correspondence address}

Leonardo C. Welling

Rua Tiradentes, 976, Centro

84010-190 - Ponta Grossa, PR, Brazil

E-mail: leonardowelling@yahoo.com.br 